\title{
ALTERNATIVAS SUSTENTÁVEIS NA PRODUÇÃO DE OVINOS
}

\author{
Murillo Ceola Stefano Pereira ${ }^{1}$
}

Rafael Silvio Bonilha Pinheiro²

RESUMO: Nos últimos anos, o conceito de desenvolvimento sustentável passou a ser amplamente utilizado pela sociedade mundial. A busca por alternativas sustentáveis e ao mesmo tempo viáveis economicamente, são estratégias buscadas para implantação e agregação de valor nos produtos oriundos da ovinocultura. Nesta revisão de literatura foram abordados temas relacionados a agroecossistemas na produção animal, integração lavoura-pecuária, alternativas sustentáveis para controle de nematódeos gastrintestinais, aproveitamento de dejetos e produção orgânica.

Palavras-chave: Meio ambiente. Ovinocultura. Produção rural.

\section{INTRODUÇÃO}

Dentre as inúmeras definições de sustentabilidade encontradas na literatura especializada, a de Conway (1988) citado por Faeth (1994) é suficiente para a interpretação do termo: sustentabilidade é a habilidade de um sistema em manter sua produtividade quando este se encontra sujeito a intenso esforço ou alterações. Assim, para manter a sustentabilidade são necessárias mudanças de atitudes e/ou direcionamento de ações por parte das gerações atuais, com a finalidade de suprir de forma razoável, as necessidades das gerações futuras (BELLIA, 1996).

\footnotetext{
${ }^{1}$ Mestrando em Ciência e Tecnologia Animal da UNESP - Campus de llha Solteira/Dracena. murillostefano@hotmail.com

${ }^{2}$ Professor Doutor do Departamento de Biologia e Zootecnia da FEIS/UNESP - Campus de llha Solteira. rafaelsbp@bio.feis.unesp.br
} 
O conceito de desenvolvimento sustentável passou a ser amplamente usado, sobretudo, a partir da Conferência das Nações Unidas sobre Ambiente e Desenvolvimento (CNUAD), que ocorreu no Rio de Janeiro em junho de 1992. Desde então, vários países instituíram o desenvolvimento sustentável como componente da sua estratégia política conjugando ambiente, economia e aspectos sociais (BARTUSKA et al., 1998).

O objetivo desta revisão de literatura foi discutir alternativas produtivas e sustentáveis que sejam mais econômicas e agreguem valor na cadeia produtiva da ovinocultura.

\section{REVISÃO DE LITERATURA}

\subsection{Agroecossistemas e produção animal}

Agroecossistemas são sistemas ecológicos modificados pelo homem para produzir comida, fibra ou outro produto agrícola. Por desenvolvimento sustentável entende-se o desenvolvimento que satisfaz as necessidades da geração presente sem comprometer as possibilidades das futuras gerações em satisfazer as suas necessidades.

O homem vem explorando agressivamente a natureza já há muitos anos como se não fizesse parte dela. Esta relação tem sido construída a partir das mudanças nas concepções do homem sobre o significado da natureza. O fato é que não podemos nos dissociar da natureza, como ser biológico que somos nem tão pouco nos distanciarmos do fato que precisamos viver em harmonia. As tentativas do homem em dominar a natureza redundaram em fracasso, produzindo na verdade, grandes e continuados eventos de degradação ambiental (HOLANDA, 2004).

Em diversos países passaram a surgir formas alternativas de se trabalhar a agropecuária, com diferentes denominações: orgânica, biológica, natural, ecológica, biodinâmica, entre outras, cada uma delas seguindo determinadas filosofias, princípios, tecnologias, normas e regras, segundo as correntes a que estão aderidas. Não obstante, 
na maioria das vezes, tais alternativas não conseguiram dar respostas para os problemas socioambientais que foram se acumulando, como resultado do modelo convencional de desenvolvimento e de agropecuária que passou a predominar, particularmente, depois da II Guerra Mundial (PGDR, 2002).

A integração da produção animal ao agroecossistema é uma estratégia para a diversificação. Nessa integração busca-se potencializar os efeitos complementares existentes entre produção vegetal e animal, utilizando-se, por exemplo, o hábito do pastejo seletivo dos animais para manejar áreas infestadas por plantas invasoras. Buscase também incrementar a ciclagem dos dois subsistemas, melhorando o aproveitamento e o uso de esterco dos animais nas áreas de lavoura e incorporando espécies de forrageiras nas áreas cultivadas. Este tipo de prática e de abordagem é bastante comum nos sistemas cuja orientação principal é a produção (UNDP, 1992).

\subsection{Integração lavoura-pecuária}

O constante aumento na demanda mundial de produtos de origem vegetal, madeira, fibras, celulose e também os de origem animal, vêm levando o setor primário a adotar processos produtivos intensivos, com a finalidade de atender tanto o mercado interno quanto as exportações.

A associação entre cultivos e produção animal em sistemas integrados é um conceito, por assim dizer, ré emergente em nível mundial (CARVALHO et al., 2006). Hoje é reconhecido que produção integrada reúne conceitos de sistemas e arranjos produtivos capazes de conferir maior estabilidade e sustentabilidade aos negócios agropecuários, em comparação com aos monocultivos intensivos, que são pouco sustentáveis, afetam negativamente a biodiversidade e promovem a fragmentação do habitat (ALTIERI, 1999).

Os sistemas integrados permitem maior diversidade nas rotações de culturas, melhor reciclagem de nutrientes e maior eficiência no uso da energia (ENTZ et al., 2005), assim, em sistemas de integração entre culturas agrícolas e pastagens, por exemplo, podem ser atingidos níveis mais elevados de produtividade em atendimento às novas exigências socioambientais. 


\section{Then

O termo integração lavoura pecuária é uma denominação brasileira a sistemas de produção que se caracterizam, principalmente, pela combinação de ciclos de agricultura com ciclos de pecuária, em sucessão na mesma área. E seus benefícios têm sido associados à redução de custos, aumento da eficiência do uso da terra, melhoria dos atributos físicos e químicos do solo, redução de pragas e doenças, aumento de liquidez e de renda (CARVALHO et al., 2005).

Em estudos realizados por Lunardi et al. (2008) avaliando a influência de métodos e intensidades de pastejo de ovinos no rendimento da soja cultivada em dois espaçamentos entre linhas, em um sistema de integração lavoura-pecuária, observaram que a presença de pastejo por cordeiros no azevém, favorece o rendimento de soja e o método de pastejo contínuo ou rotacionado não são determinantes no rendimento da soja.

\subsection{Nematódeos gastrintestinais}

A verminose representa o maior e mais grave problema sanitário na ovinocultura, e podem inviabilizar economicamente a criação em muitas regiões do mundo.

Os animais são parasitados por diferentes espécies ao mesmo tempo e as mais importantes e comuns nas regiões tropicais são: Haemonchus contortus, Trichostrongylus colubriformis, Strongyloides spp., Cooperia spp. e Oesophagostomum columbianum (AMARANTE et al., 1997). Entre essas espécies, a mais importante é o Haemonchus contortus, parasito do abomaso, representante da família Trichostrongylidae caracterizase por ser essencialmente hematófago e muito prevalente no Brasil (AMARANTE, 2001).

Entre os métodos de controle de endoparasitos conhecidos, o mais utilizado continua sendo o químico, entretanto, falhas na utilização desse método têm favorecido o aparecimento de cepas de parasitos resistentes aos anti-helmínticos comerciais (SANGSTER, 2001).

Conder e Campbell (1995) definiram a resistência anti-helmíntica como um fenômeno pelo qual um princípio ativo não consegue manter a mesma eficácia contra os parasitos, se utilizado nas mesmas condições, após determinado período. A situação é alarmante em países como Argentina, Paraguai, Uruguai e Brasil onde se encontram os maiores níveis de resistência anti-helmíntica do mundo (LARA, 2003). Por esta razão, 
novas estratégias devem ser utilizadas (utilização de produtos naturais), afim de, reduzir o controle químico e consequentemente reduzir os problemas com a resistência parasitaria.

\subsection{Raças resistentes e seleção de animais resistentes}

Algumas raças de ovinos demonstram resistência genética contra as infecções por nematódeos gastrintestinais ou mesmo, animais da mesma raça.

Nos EUA, ovinos da raça Florida Native apresentam grande resistência às infecções por Haemonchus contortus quando comparados a ovinos da raça Rambouillet (AMARANTE et al., 1999). Da mesma forma, as raças Red Masai e Blackhead Persian, criadas no Quênia (África), demonstram maior resistência às infecções por Haemonchus contortus do que as raças Merino, Dorper, Corriedale e Hampshire (PRESTON e ALLONBY, 1979).

No Brasil, as raças ovinas foram introduzidas provavelmente logo após o descobrimento do país. Os descendentes desses ovinos deram origem a raças que se caracterizaram por apresentar grande rusticidade. Estudos realizados no Rio Grande do Sul, com rebanhos remanescentes da raça Crioula têm demonstrado que a resistência às infecções por Haemonchus. contortus é muito superior nos animais desta raça do que nos animais da raça Corriedale (BRICARELLO, 1999).

Na região nordeste são criados principalmente ovinos deslanados da raça Santa Inês. Esses ovinos são desprovidos de lã e são conhecidos no nordeste brasileiro há mais de um século e meio. Os ovinos desta raça (Santa Inês) apresentam grande rusticidade e produzem carne e peles de qualidade (JARDIM, 1987).

Os helmintos não se distribuem de maneira uniforme em um rebanho ovino mesmo que os animais sejam de mesma raça e idade. Os parasitas apresentam distribuição binomial negativa, ou seja, a maioria dos hospedeiros alberga poucos parasitas, enquanto alguns animais albergam a maior proporção da população total de parasitas.

A resistência aos parasitas é herdável geneticamente. Apesar do grande número de raças e espécies estudadas, as estimativas dos valores de herdabilidade para resistência aos helmintos em ovinos são muito consistentes, variando de 0,3 a 0,5 (BARGER, 1989). 
A utilização de ovinos resistentes tem demonstrado influência benéfica na epidemiologia das infecções por nematódeos gastrintestinais em ovinos. Com isso, a utilização de animais geneticamente resistentes pode permitir a redução na frequência dos tratamentos (utilização de produtos químicos) anti-helmínticos, que além da economia para o ovinocultor permite reduzir a velocidade no surgimento de populações de nematódeos resistentes aos anti-helmínticos (AMARANTE e SALES, 2007).

\subsection{Lotação de pastagens}

A melhoria das pastagens, por meio da introdução de plantas forrageiras e do emprego de fertilizantes, tem contribuído para o melhor aproveitamento dos pastos, permitindo uma maior lotação das pastagens e um sistema rotacionado se mostra uma alternativa viável para esse aumento. Portanto as lotações elevadas facilitam a transmissão dos parasitas favorecendo a ocorrência da verminose.

Como a rotação permite aumentar o número de animais em uma área, pode ocorrer, na verdade, aumento da contaminação. Portanto, a vigilância em relação à verminose deverá ser redobrada quando esses sistemas de pastejo são empregados.

Em algumas circunstâncias esse sistema de manejo pode ter algum efeito benéfico especialmente nos períodos do ano com temperatura ambiental elevada. As temperaturas elevadas, ao mesmo tempo em que aceleram o desenvolvimento larval (ovo até larva infectante), podem reduzir o tempo de sobrevivência das larvas no ambiente (AMARANTE e SALES, 2007).

Em experimento realizado em laboratório, em que larvas infectantes de $T$. colubriformis foram mantidas na água em temperatura constante. Andersen et al. (1966) demonstrou que após 32 dias de estocagem em temperaturas que variaram de $4{ }^{\circ} \mathrm{C}$ a 25 ${ }^{\circ} \mathrm{C}$ a sobrevivência das larvas foi superior a $98 \%$. Em temperaturas mais elevadas 0 tempo de sobrevivência foi menor $\left(95 \%\right.$ a $30^{\circ} \mathrm{C} ; 73 \%$ a $\left.35^{\circ} \mathrm{C}\right)$ e não houve sobrevivência após as larvas terem sido mantidas durante 32 dias a $40{ }^{\circ} \mathrm{C}$.

Em Petrolina-PE, região semiárida nordestina, a falta de umidade é o fator limitante à transmissão dos nematódeos em ovinos. Nessa região a precipitação é muito baixa (350 a 400 mm/ano) e se distribui irregularmente de novembro a abril. Nos meses secos a 
transmissão dos nematódeos é inexpressiva (CHARLES, 1989). Já na região de Botucatu-SP ocorre exatamente o contrário. Verifica-se que as condições climáticas são favoráveis ao desenvolvimento e sobrevivência dos estágios de vida livre dos nematódeos na pastagem, ao longo de todo o ano (AMARANTE e BARBOSA, 1995).

\subsection{Descontaminação da pastagem pelo uso de diferentes espécies de herbívoros}

Este método consiste em alternar em um pasto diferentes espécies de hospedeiros. Esta técnica fundamenta-se no fato de que as espécies de nematódeos gastrintestinais apresentam o que se denomina especificidade parasitária.

Embora essa especificidade seja variável conforme a espécie do parasita, a grande maioria das espécies que parasitam ovinos não se desenvolvem em bovinos ou em equinos e vice-versa (Amarante et al., 1997; BAGNOLA JUNIOR. et al., 1996). Porém, para que seja efetivo, faz se necessário que cada uma das espécies de animais envolvidas no programa permaneça num piquete por períodos relativamente longos, ou seja vários meses. Para retardar a contaminação de uma pastagem "limpa", os animais, antes de serem introduzidos no piquete, devem ser tratados com vermífugo que propicie redução efetiva da carga parasitária, tarefa cada vez mais difícil devido à resistência antihelmíntica (AMARANTE et al., 1992).

\subsection{Aproveitamento de dejetos dos animais}

O manejo inadequado ocasionado pelos dejetos é um grave problema, podendo atuar como vetor de doenças e contaminar a água e o solo. Uma alternativa para evitar esses problemas é o aproveitamento do esterco, normalmente com baixo valor comercial, pode ser utilizado como biofertilizante na geração de energia renovável, constituindo uma ferramenta importante para o desenvolvimento sustentável, contribuindo com a renda dos produtores e a preservação do meio ambiente. Assim, o uso da adubação orgânica, em substituição total ou parcial da adubação química, permite diminuir os custos de produção, produzir alimento mais saudável e evitar ou diminuir os riscos ambientais. 
A produção diária do biofertilizante permite substituir adubos químicos a base de sulfato de amônio, superfosfato simples e cloreto de potássio. Além de ser utilizado como biofertilizante, o esterco pode ser usado para produzir energia renovável, mediante a utilização de biodigestores, contribuindo com uma produção de energia limpa e sustentável.

\subsection{Produção orgânica}

Nos anos 60 e 70, a agricultura mundial foi impulsionada com chamada "Revolução Verde", foi quando as práticas de mecanização correção e fertilização do solo, assim como a utilização de agrotóxicos contra pragas e doenças, impulsionaram a produção mundial de alimentos para patamares nunca antes experimentados (VITTI e LUZ, 2004).

Esses novos anseios que envolviam a produção de alimentos despertaram o mundo para sistemas de produção mais conservacionistas, e a palavra ecologia ganhou significado especial. Surgem, então, os sistemas alternativos com propostas ambiciosas para a produção de alimentos em harmonia com o meio ambiente. Em comum, todas apresentam forte preocupação com os destinos inseparáveis do homem e do meio ambiente, sendo a agricultura orgânica a mais conhecida desse segmento (ARAÚJO FILHO e VASCONCELOS, 2003).

A produção de alimentos orgânicos é algo inovador, inclusive para o agricultor familiar, em decorrência da baixa dependência por insumos externos, pelo aumento de valor agregado ao produto com consequente aumento de renda para o agricultor e por propiciar a conservação dos recursos naturais.

Nos últimos anos, o mercado brasileiro de produtos orgânicos tem se expandido a uma taxa de $40 \%$ ao ano, e estima-se que hoje este mercado represente $2 \%$ da produção agrícola brasileira. A área cultivada ainda é pequena. De acordo com o Agrianual (2000), são cerca de 100 mil ha área muito menor do que a ocupada pela agricultura orgânica na Argentina, que já chega a 380 mil ha.

Os alimentos orgânicos de origem animal são comercializados em pequena escala (feiras, lojas e em domicílio), em virtude das exigências da legislação sanitária para serem industrializados em pequenas estruturas, e posteriormente serem colocados em um 
grande canal varejista. As legislações estadual e municipal vêm facilitando as ações de pequenos agricultores e agroindústrias de pequeno porte, tanto para os alimentos de origem vegetal, quanto animal (FONSECA, 2000).

A produção orgânica faz parte das prioridades do governo. Em novembro de 2003, foi sancionada a Lei 10.831 (BRASIL, 2003), que caracteriza a agricultura orgânica nacional. Em março de 2004, foi criada a Câmara Setorial da cadeia produtiva da Agricultura Orgânica, com o objetivo de incentivar a produção e a comercialização de produtos orgânicos.

O Ministério da Agricultura Pecuária e Abastecimento, através da Instrução Normativa 007 , estabeleceu uma série de procedimentos para que o produto de origem animal seja considerado orgânico. Esses procedimentos regulamentam a alimentação do rebanho, as instalações, o manejo, a escolha de animais, a sanidade e até $o$ processamento e empacotamento do leite (BRASIL, 2003).

Em geral, como em qualquer sistema de produção, recomenda-se que a alimentação seja equilibrada e supra todas as necessidades dos animais. Os suplementos devem ser isentos de antibióticos, hormônios e vermífugos. São proibidos aditivos, promotores de crescimento, estimulante de apetite, ureia e etc. As características de comportamento (etológicas) de cada espécie a ser explorada devem ser consideradas. Os produtores devem ainda estar atentos para os produtos empregados na lavagem e desinfeção dos equipamentos e utensílios (ALMEIDA, 2000).

De acordo com os princípios da agricultura orgânica, a atividade animal deve estar, tanto quanto possível, integrada à produção vegetal, visando a otimização da reciclagem dos nutrientes (dejetos animais e biomassa vegetal), a menor dependência de insumos externos (rações e volumosos) e a potencialização de todos os benefícios diretos e indiretos advindos dessa integração.

\section{CONSIDERAÇÕES FINAIS}

A maioria dos sistemas de produção de ovinos apresentam condições favoráveis para serem sustentáveis, permitindo menor dano ao meio ambiente e à sociedade. 


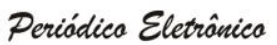

As alternativas sustentáveis na produção de ovinos abordadas nesta revisão, são de fácil aplicação e podem ser melhoradas com tecnologias simples, de baixo custo e de fácil aplicação, evitando dano ao meio ambiente e agregando valor ao produto final.

\section{REFERÊNCIAS}

AGRIANUAL: Anuário da Pecuária Brasileira. São Paulo: INP Consultoria e Comércio, 2000.

ALMEIDA, L.A.B. Normatização e certificação de produtos orgânicos, leite e derivados. In: BRESSAN, M.; MARTINS, C. E.; VILELA, D. (Ed.). Sustentabilidade da pecuária de leite no Brasil. Juiz de Fora: Embrapa Gado de Leite, 2000. p.165-174.

ALTIERI, A.M. The ecological role of biodiversity in agroecosystems. Agriculture, Ecosystems and Environmet, v.74, p.19-31, 1999.

AMARANTE, A.F.T. et al. Efeito da administração de oxfendazol, ivermectina e levamisol sobre os exames coproparasitológicos de ovinos. Brazilian Journal of Veterinary Research and Animal Science, v.29, n.1, p.31-38, 1992.

AMARANTE, A.F.T.; BARBOSA, M.A. Seasonal variations in populations of infective larvae on pasture and nematode faecal egg output in sheep. Veterinária e Zootecnia, v.7, p.127-133, 1995.

AMARANTE, A.F.T. et al. Host specificity of sheep and cattle nematodes in São Paulo State, Brazil. Veterinary Parasitology, v.73, p.89-104, 1997.

AMARANTE, A.F.T. et al. Comparison of naturally acquired parasite burdens among Florida Native, Rambouillet and crossbreed ewes. Veterinary Parasitology, v.85, p.6169, 1999.

AMARANTE, A.F.T. Controle de endoparasitoses dos ovinos. In: REUNIÃO ANUAL DA SOCIEDADE BRASILEIRA DE ZOOTECNIA, 3., Piracicaba. Anais... Piracicaba: Sociedade Brasileira de Zootecnia. 2001. p.461-471. 
AMARANTE, A.F.T.; SALES, R.O. Controle de Endoparasitoses dos Ovinos: Uma Revisão. Revista Brasileira de Higiene e Sanidade Animal, v.01, p.14 - 36, 2007.

ANDERSEN, F.L.; WANG, G.T.; LEVINE, N.D. Effect of temperature on survival of the free-living stages of Trichostrongylus colubriformis. The Journal of Parasitology, v.52, p.713-721, 1966.

ARAÚJO FILHO, J.A. de; VASCONCELOS, H.E.M. Produção orgânica de carne de ovinos e caprinos. In: SIMPÓSIO INTERNACIONAL SOBRE O AGRONEGÓCIO DA CAPRINOCULTURA LEITEIRA, 1.; SIMPÓSIO INTERNACIONAL SOBRE CAPRINOS E OVINOS DE CORTE, 2.; ESPAÇO APRISCO NORDESTE, 1., 2003, João Pessoa. Anais... João Pessoa: EMEPA, 2003. p.233-242.

BAGNOLA JUNIOR, J.; AMARANTE, A.F.T.; MAYER, L.F.F. Verminose em eqüinos: exames coprológicos, contaminação da pastagem e pastejo alternado com ovinos. Veterinária e Zootecnia, v.8, n, p.47- 57, 1996.

BARGER I.A. Genetic resistance of hosts and its influence on epidemiology. Veterinary Parasitology, v.32, p.21-35, 1989.

BARTUSKA, T.J.; KAZIMEE, B.A.; OWEN, M.S. Defining sustainability. In: COMMUNITY SUSTAINABILITY: A COMPREHENSIVE URBAN REGENERATIVE PROCESS/A PROPOSAL FOR PULLMAN WASHINGTON, USA. Washington: School of Architecture/Washington State University, 1998. n.p.

BELLIA, V. Introdução à economia do meio ambiente. Brasília: IBAMA. 1996. 262p.

BRASIL. Lei no 10831, de 23 de dezembro de 2003. Dispõe sobre a agricultura orgânica e dá outras providências. Diário Oficial [da] República Federativa do Brasil, Poder Executivo, Brasília, DF, 23 dez. 2003. Seção 1, p. 8.

BRICARELLO, P.A. Alterações hematológicas, bioquímicas, parasitológicas e histológicas de ovinos das raças Corriedale e Crioula Lanada frente à infecção primária artificial e natural por Haemonchus contortus. Porto Alegre, 1999. 141p. Dissertação (Mestrado em Medicina Veterinária,) Faculdade de Veterinária, Universidade Federal do Rio Grande do Sul. Porto Alegre, 1990. 
CARVALHO, P.C.F. et al. O estado da arte em integração lavoura-pecuária. In:

GOTTSCHALL C.S.; SILVA, J.L.S.; RODRIGUES, N.C. (Org.). Produção animal: mitos, pesquia e adoção de tecnologia. Canoas: Editora da ULBRA, 2005, p.7-44.

CARVALHO, P.C.F. et al. Manejo da integração lavoura-pecuária para a região de clima subtropical. In: ENCONTRO NACIONAL DE PLANTIO DIRETO NA PALHA, 10., 2006, Uberaba. Anais... Uberaba, 2006. p.177-184.

CHARLES, T.P. Seasonal prevalence of gastrointestinal nematodes of goats in Pernambuco State, Brazil. Veterinary Parasitology, V.30, P.335-343, 1989.

CONDER, G.A.; CAMPBELL, W.C. Chemoterapy of nematode infections of veterinary importance, with special reference to drugresistance. Advances in Parasitology, v.35, p.1-83, 1995.

ENTZ, M.H et al. Evolution of integrated crop-livestock production systems. In: McGilloway, D.A. (Org.). Grassland: a global resource. Wageningen, p.137-148. 2005.

FAETH, P. Análisis económico de la sustentabilidad agrícola. Agroecología y Desarrollo, n.7, p.32-41, 1994.

FONSECA, L.F.L., SANTOS, M.V. Qualidade do leite e controle de mastite. 1.ed. São Paulo: Lemos Editorial, 2000. 175p.

HOLANDA, F.S.R. A Ética ambiental e a sustentabilidade de agroecossistemas. Ciências Ambientais \& Desenvolvimento. v.1, n.1, 2004.

JARDIM, W.R. Os ovinos. 4 ed. Livraria Nobel, São Paulo, 1987. 193 p.

LARA, D.M. Resistencia a los antihelmínticos: origen, desarrollo y control. Revista Corpoica, v.4, p.55-71, 2003.

LUNARDI, R. et al. Rendimento de soja em sistema de integração lavoura-pecuária: efeito de métodos e intensidades de pastejo. Ciência Rural, v.38, n.3, p.795-801, 2008. 
PGDR, Glossário Evolutivo Comum. In: Evolução e diferenciação da agricultura, transformação do meio natural e desenvolvimento sustentável em municípios da Planície Costeira e Planalto Sul-rio-grandense: uma abordagem interdisciplinar. (Relatório de Pesquisa). Porto Alegre: UFRGS, 2002.

PRESTON, J.M.; ALLONBY, E.W. The influence of breed on the susceptibility of sheep to Haemonchus contortus infection in Kenya. Pesquisa em Ciência Veterinária, v.26, p.134-139, 1979.

SANGSTER, N.C. Managing parasiticide resistance. Veterinary Parasitology, v.98, p.89109, 2001.

UNDP, Programa das nações unidas para o desenvolvimento, 1992. Disponível em http://www.undp.org.br/. Acessado em: 28 mai. 2013.

VITTI, G.C.; LUZ, P.H.C.de. Utilização agronômica de corretivos agrícolas. Piracicaba: FEALQ, 2004. 120 p. 